\title{
Design and Implementation of a Practical FTTH Network
}

\author{
Dheyaa Jasim Kadhim \\ Department of Electrical Engineering \\ Baghdad University, Iraq.
}

\author{
Nahla Abdul-Rahman Hussain \\ Department of Electrical Engineering \\ Baghdad University, Iraq.
}

\begin{abstract}
Fiber-to-the-Home (FTTH) has long been recognized as a technology that provides future proof bandwidth [1], but has generally been too expensive to implement on a wide scale. However, reductions in the cost of electro-optic components and improvements in the handling of fiber optics now make FTTH a cost effective solution in many situations. The transition to FTTH in the access network is also a benefit for both consumers and service providers because it opens up the near limitless capacity of the core long-haul network to the local user. In this paper individual passive optical components, transceivers, and fibers has been put together to form a complete FTTH network. Then the implementation of the under construction Baghdad/Al-Gehad FTTH network is presented according to the available information from Iraq Telecommunication Post and Company (ITPC). In this work designing, planning and deploying of FTTH network based on Gigabit Passive Optical Network (GPON) will be evaluated in order to obtain an optimal practical sample when designing and implementing any FTTH network.
\end{abstract}

\section{Keywords}

Passive Optical Network (PON), Fiber To The Home (FTTH), Gigabit Passive Optical Network (GPON).

\section{INTRODUCTION}

High Speed Broadband (HSB) deployments are frequently justified primarily by today's applications rather than anticipated demands. For instant, streaming video content is considered by many as the ultimate bandwidth hungry application. When one adds the bandwidth requirements of one High Definition Television (HDTV) stream, a few standard definition streams and Internet browsing, it may seem that 20-30 Mbps of bandwidth is sufficient in the long term.

FTTH technology provides residences with high speed broadband access to digital services and the Internet. The FTTH networks have now established their economic competitiveness by providing significantly reduced operating expenses and enhanced revenue opportunities for carriers. In addition, a FTTH solution based on Wavelength Division Multiplexing (WDM), or a $\lambda$ - based structure, allows for additional flexibility and adaptability to support future services [2]. FTTH network has very useful property it is the distributed architecture in manner of several varieties of splitters located at different strategic places in the network [3]. For example, at the first power dividing point the optical splitters might range in size from 1:8 to 1:2. Typical secondary splitter sizes near the subscribers might range in size from $1: 4$ to $1: 16$. The main motivation for this architecture is to minimize the amount of optical cable that is needed for the distribution and drop fibers, which provides a low initial cost of the outside cable plant when implementing a FTTH network.

Many researchers wrote on the scope of FTTH. In [4] Economic aspect of projects and/or solutions in telecommunication networks is discussed and the authors found that the GPON is the more suitable to implement FTTH than other networks. In [5] a comprehensive cost modeling of FTTH was presented, which includes outside plan, head end, and premises equipment and labor with enhanced reach and split ratio and estimate cost as associated with passive and active equipment and components for the typical FTTH PON. The aim of [6] is to enhance the quality of service offered by standard passive optical networks with reduced network costs. To that extent, a dynamic multi-wavelength protocol has been developed to increase the network upstream bandwidth and introduce multiple service levels to a Fiber To The Homebased through a Gigabit Passive Optical Network (GPON).

In this paper, studying, designing and implementing of FTTH network based on GPON architecture through taking Baghdad/Al-Gehad as a study case which it is one of the Iraq Telecommunications and Post Company (ITPC) FTTH projects in Iraq. A studying of the required number of PON network ports is introduced in terms of take rate with fixed amount of cycle time to support multiple services and to guarantee adequate transport capacity per subscriber in AlGehad FTTH network. Cost optimization is introduced for feeder cables, distribution cables and total cost of Al-Gehad FTTH network through the GPON technology with respect to the number of subscribers.

The rest of this paper is structured as follows section II will illustrate FTTH architecture. Section III illustrates the access network and in section IV, we present the components of FTTH network. Conclusion is presented in section V.

\section{ITPC ACCESS NETWORK ARCHITECTURE}

Cater to the needs of large bandwidth and High Speed Internet (HIS) of users, Iraq Telecommunication Post and Company (ITPC) has built the national project of FTTH network in Baghdad and takes advantage of the existing infrastructure resources of fiber optic networks such as the central offices, PDN networks, etc. ITPC FTTH access network consists of four layers as shown in Figure (1), these four layers are:

1. Application layer: it could be called service level since it represents providing services such as High Speed Internet (HIS), Voice over IP (VoIP) and so on.

2. Core layer: it is the backbone of passive distribution network (PDN), it contains core routers. 
3. Convergence layer: consists of the following components:

a. Provider Routers (P) Routers.

b. Provider Edge (PE) routers.

c. Broadband Remote Access Server (BRAS) it is double up link to the Cisco PE Router and contains LAN interface card, electrical interface card and optical interface card. It supports the security filtering feature, the hardware based wire speed NAT function and load balancing. The data flow comes from OLT to the cisco PE Router to BRAS then to Passive Distribution Network (PDN) as it is clear in Figure (2).

d. Authentication Server (AAA): consists of Data base (DB) server to store user data including user name, user password and user authentication information. It achieves the user identities, control the user access to different services and support roaming authentication and authorization in Point to Point over Ethernet (PPoE) authentication process.

e. Element Management System (EMS) and Network Management System (NMS) and layer three switches: they can manage the network and data equipment of service layer, core layer, convergence layer, access layer and terminal layer in a centralized way. Also it provides centralized operation and maintenance capabilities for all devices and network. Management server provides function as user management accounting, web services, etc.

4. Access layer: consists of OLT, splitter and ONT. This layer will be explained in more details than the other layers, since the part that has been implemented in Al-Gehad FTTH network represents the access layer.

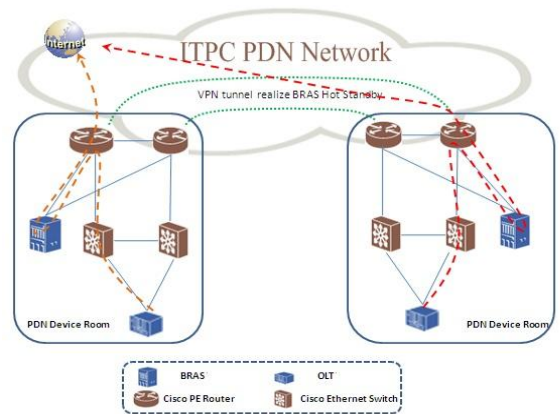

Figure 2. Data Flow

\section{DESIGN OF Al-GEHAD FTTH}

\section{NETWORK}

Passive Optical Network (PON)-based Fiber-To-The-Home (FTTH) is a solution that can break through the economic barrier of traditional point-to-point solutions. Figure (3) shows PON-based FTTH system architecture where a PON connects several Optical Network Terminations (ONTs) in customer premises and an Optical Subscriber Unit (OSU) to an Optical Line Termination (OLT) in Central Office (CO) through a passive optical splitter. PONs are usually based on a tree topology between the Optical Line Terminal (OLT) and the Optical Network Units (ONUs).

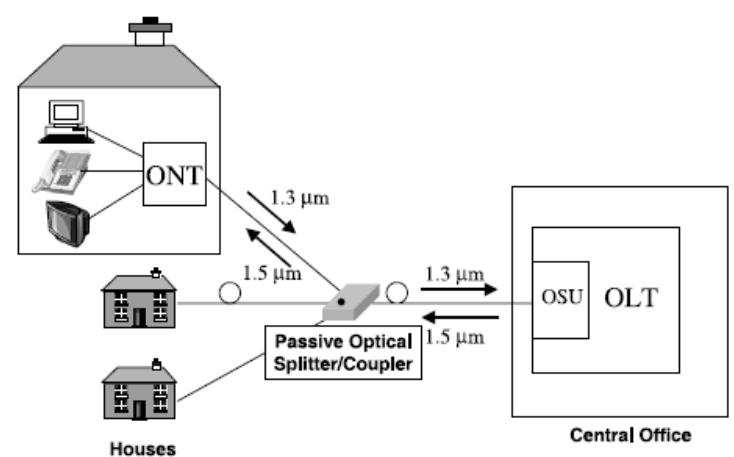

Figure 3. FTTH Architecture

The OLT is located at the local exchange and connects the access to the metro backbone. An ONT is used when the fiber extends into the customer premises, whereas an ONU is used when the fiber line terminates in some type of telecommunication cabinet located near a cluster of homes or businesses. Connections from the ONU to the premises can be by means of media such as twisted-pair wires (e.g., telephone lines or digital subscriber links) or coaxial cable [7]. When an ONU resides at the curb, the access system called Fiber To The Curb (FTTC), or it resides at the end user location the system called Fiber To The Home (FTTH) or building, called Fiber To The Building (FTTB). So, all fiber access systems could be called FTTx. All these types of PON architecture is shown in Figure (4).

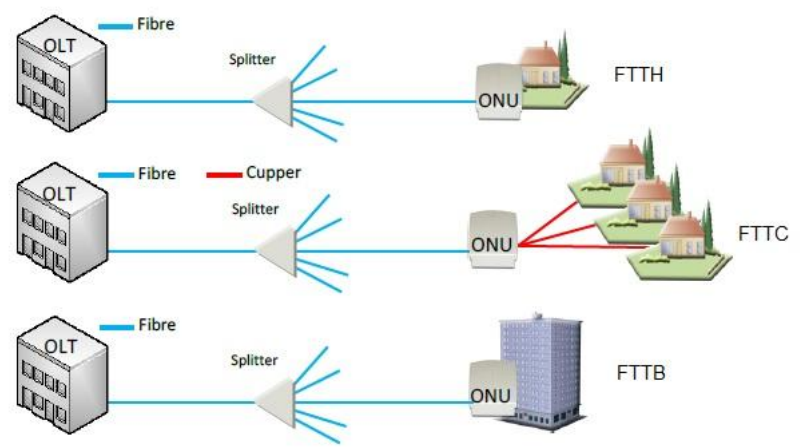

Figure 4. Fiber To The $x($ FTTx)

The simplest method of transmission is to use Time-Division Multiple Access (TDMA), wherein each user transmits information within a specific assigned time slot at a prearranged data rate. A Wavelength Division Multiplexing PON (WDM-PON) uses a passive WDM coupler as the remote terminal. Signals for different ONUs are carried on different wavelengths $(1.3 \mu \mathrm{m}$ in downstream direction and $1.5 \mu \mathrm{m}$ for upstream direction) and routed by the WDM coupler to the proper ONU. Since each ONU only receives its own wavelength, WDM-PON has better privacy and better scalability [8].

Because ATM cells from ONTs are combined into one cell stream to the OSU after the optical splitter/coupler, there may be collision among upstream cells from different ONTs unless there is a Media Access Control (MAC) protocol to 
coordinate their transmission. So TDM-based MAC is used with a frame structure for collision-free upstream transmission on the PON. Note that in downstream transmission there is no such a conflict.

\subsection{Optical Distribution Network (ODN)}

For FTTH solution the access layer will provide OLT equipment in exchange; all subscribers will be connected through Optical Distribution Network (ODN). The proposed connection will be from the OLT to access point Fiber Access Terminal distribution box (FAT)

As it is obvious from Figure (5) the FTTH system comprises the Optical Line Terminal (OLT) on the Central Office (CO), the Optical Network Terminal (ONT) on the user side, and the Optical Distribution Network (ODN). The FTTH construction features the PON technology, which provides point to point and point to multi-point applications. ODN provides the physical channels from OLT and ONT to communicate with each other.

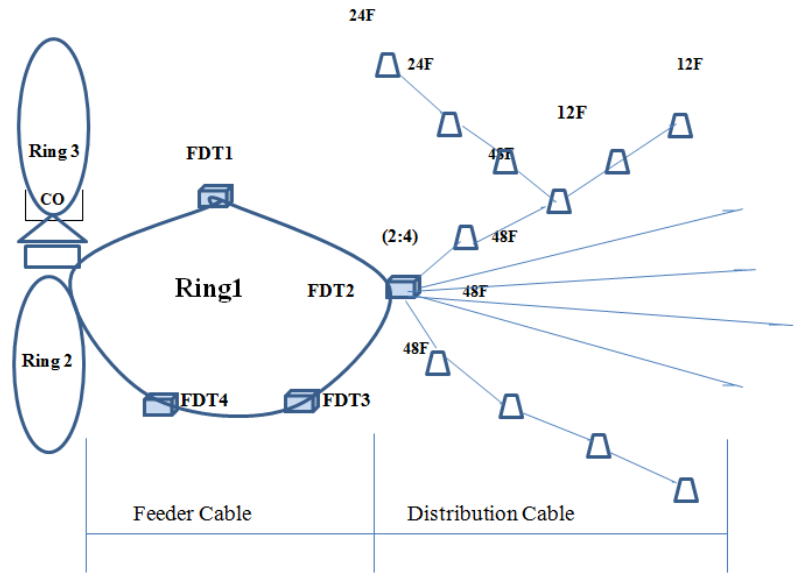

Figure 5. OLT Connection from OLT to Terminal Distribution Box

The Optical Distribution Network (ODN) can be divided into four parts from the $\mathrm{CO}$ end to the user end: feeder cable subsystem, distribution cable subsystem, drop cable subsystem and optical terminal subsystem.

The access network and related BRAS/AAA/EMS will connect to ITPC Passive Distribution Network (PDN) network and work as one part of ITPC national broadband network. In the central offices, the PDN network some is ready, some is not ready. Even the PDN network is ready; it needs expansion for FTTH access network. In each central office, two layer 3 switches (active/standby) aggregate the Gigabit Ethernet Interface (GE) interfaces of OLT and connect to the two routers (active/standby) by 10GE interfaces. In the core central office the PDN network also is responsible for the connection of BRAS/AAA.

\subsection{Al-Gehad FTTH Network Topology}

According to the information from ITPC, the FTTH network in Al-Gehad is consists of two OLTs placed in Al-Gehad exchange (CO) will be serve 6000 subscribers in total area of about $32 \mathrm{~km} 2$. It has been planned to use 6000 ONTs, one ONT per subscriber. Each OLT will connect to the converged
Layer 3 switches and then the routers to ITPC Passive Distribution Network (PDN) network. The length of feeder cables is $243 \mathrm{~km}$ and the length of distribution cables is $405 \mathrm{~km}$, so the total fiber cables length will be $647 \mathrm{~km}$.

After studying and summarizing the varying building features and application scenarios of the detail site survey, and based on the requirement of IPTC, the design will be as follow:

a. For general network topology, a ring topology is used to deploy the FTTH passive network, offer the protection to Optical Distribution Network (ODN).

b. There is $20 \%$ spare capacity in the feeder cables, from the Central Office up to the Fiber Distribution Terminal (FDT), to meet the future requirements.

c. Feeder section from CO to FDT, 144F optical cable will be proposed by ring topology and 2:4 first level splitter will be proposed in FDT cabinet.

d. Distribution section from FDT to Fiber Access Terminal (FAT) is $72 \mathrm{~F}, 48 \mathrm{~F}, 24 \mathrm{~F}$, and $12 \mathrm{~F}$ optical cable will be proposed by star topology and 1:16 second level splitter will be proposed in FAT, which is closure to wall mounted FAT product to meet different requirement and scenarios.

Design and implementation Al-Gehad FTTH network will be illustrate using the information that has been obtained from ITPC. Figure (6) shows the network topology logical diagram that will be used to implement Al-Gehad FTTH network. Two topologies are used, ring topology for feeder cables that are connect the Fiber Distribution Terminals (FDTs) to the Central Office (CO) by first level splitting of 2:4, and star topology to connect several numbers of Fiber Allocation Terminal (FAT) to each FDT by second level splitting of $1: 16$.

OLT will be deployed in each central office and the quantity will be calculated to satisfy the coverage capacity. Each OLT will connect to the converged Layer 3 switches and then the routers to ITPC PDN network. BRAS will be installed in the core central offices. BRAS are full load configuration with the processing capability of not less than 115,000 lines. In the normal status, each BRAS just take the service traffic which belong to the corresponding areas. When one is broken, the other BRAS will take the whole service. AAA is the same with BRAS. EMS remote redundancy is ensuring the reliability.

\section{IMPLEMENTATION OF Al-GEHAD FTTH NETWORK}

Optical distribution network is placed in Al-Gehad exchange. ODN contain two components, the first one is fiber distribution terminal (FDT) and the second one is fiber access terminal (FAT). Usually DFT called cabinet, its dimension is $60 \mathrm{~cm}$ (width) $* 500 \mathrm{~cm}$ (hight) $* 40 \mathrm{~cm}$ (depth). It connected to OLT in CO in ring topology from one side, and the other side connects to the FAT in star topology.

The number of FDT can be calculated from the following relation:

No. of FDT $=$ No. of Fibers in Feeder Cable/8

In Al-Gehad FTTH network the feeder cable of (144) fibers so, according to the relation above the number of FDT in AlGehad FTTH network is (16) FDT, and the number of Fiber 
Access Terminal (FAT) is $8 * 4=32 \mathrm{FAT} / \mathrm{FDT}$. And each FAT serves 16 subscribers. So, each FDT serves $32 * 16=512$ subscribers/DFT, and we have 16 DFT, so the total number of subscribers that can be served in Al Gehad FTTH network is $512 * 16=8192$ subscribers.

Al-Gehad FTTH Optical Distribution Network (ODN) consists of several components they will be illustrated and explained briefly.

\subsection{0ptical Network Terminal (ONT)}

In Al-Gehad FTTH network there is one Optical Network Terminal (ONT) for each subscriber premise. This ONT with $4 \times 10 / 100 / 1000$ Base- $T$ Ethernet Interfaces and $2 \times \mathrm{RJ}-11$ can satisfy one single family enjoying Voice over IP (VoIP) and High Speed Internet (HIS). Table (1) illustrates Al-Gehad FTTH network ONT specifications.

Table 1.Specifications of GPON ONT

\begin{tabular}{|l|l|}
\hline \multicolumn{1}{|c|}{ Item } & \multicolumn{1}{c|}{ Specification } \\
\hline Downstream Bandwidth & $2.488 \mathrm{Gbit} / \mathrm{sec}$ \\
\hline Upstream Bandwidth & $1.244 \mathrm{Gbit} / \mathrm{sec}$ \\
\hline Uplink Interface & $1 \mathrm{GPON}$ interface \\
\hline Subscriber Interface & $\begin{array}{l}4 * 10 / 100 / 1000 \text { Base-T Ethernet } \\
\text { Interface, } 2 * \mathrm{RJ}-11\end{array}$ \\
\hline Dimension & $185 \mathrm{~mm}(\mathrm{~W}) * 50 \mathrm{~mm}(\mathrm{H}) * 260 \mathrm{~mm}(\mathrm{D})$ \\
\hline Power consumption & $10 \mathrm{~W}$ \\
\hline Weight & $<1 \mathrm{~kg}$ \\
\hline Power supply & $\begin{array}{l}\text { Input: } 100 \sim 240 \mathrm{VAC} \\
\text { Output: } 12 \mathrm{VDC}\end{array}$ \\
\hline Work temperature & $-5 \mathrm{C} \sim 55 \mathrm{C}$ \\
\hline Work Humidity & $5 \% \sim 95 \%$ \\
\hline Mounting mode & Desktop \& wall mounting \\
\hline
\end{tabular}

\subsection{Optical Line Terminal (OLT)}

Optical Line Terminal (OLT), as the convergence point, should have the high density, high capacity and high reliability. An OLT with two uplink cards connects with two Layer 3 switches of ITPC PDN. The two cards work on active/standby mode for uplink protection. Each card has four Gigabit Ethernet (GE) optical interfaces of which two are used and another two are for future expansion. The Layer3 switches aggregate all the GE uplink interfaces from the same OLT central office and connect with the upper router using 10GE interfaces. Al-Gehad FTTH network OLT can support 4096 ONTs (i.e. subscribers) with the two level splitting first level is 2:4 and the second level is 1:16. The two OLTs will support 8192 ONTs. Figure (7) shows the OLT in Al-Gehad exchange. The total number of the possible serving subscribers which is 8192 exceeds the required number of the existing subscribers which is 6000 subscribers; this is due to the possibility of future growth in the network.
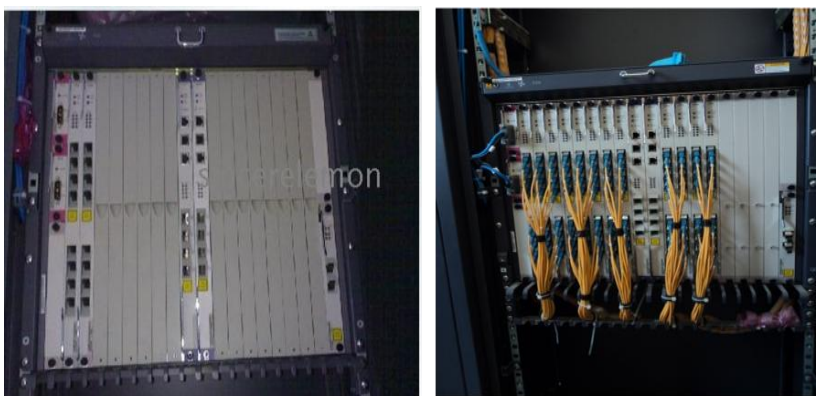

Figure 7. Al-Gehad FTTH Network OLT

Al Gehad FTTH network presents two types of services voice (VoIP) and High Speed Internet (HSI). Last card in the OLT contain these two services. In case of adding more services in future, this card is changed according to the type of presented services. The OLT specifications can be listed in Table (2).

Table 2. Specifications of GPON OLT

\begin{tabular}{|l|l|}
\hline \multicolumn{1}{|c|}{ Item } & \multicolumn{1}{c|}{$\begin{array}{c}\text { Specification } \\
\text { Capacity }\end{array}$} \\
\hline Uplink Interface & GE 16,384 ONU/ONTs $/$ E1/T1/STM-1/STM-4/OC3 \\
\hline PON Interface & EPON/GPON/P2P/10GEPON \\
\hline Split ratio & $1: 128$ \\
\hline Physical Reach & $>20 \mathrm{~km}$ \\
\hline Dimensions & $447.2 \mathrm{~mm}(\mathrm{H}) * 530 \mathrm{~mm}(\mathrm{~W}) *$ \\
& $275.8 \mathrm{~mm}(\mathrm{D})$ \\
\hline Power supply & $-48 \mathrm{~V}( \pm 20 \%) /-60 \mathrm{~V} \mathrm{DC}( \pm 20 \%)$ or \\
& $220 \mathrm{~V} \mathrm{AC}( \pm 20 \%, 50 \mathrm{~Hz})$ \\
\hline Work Temperature & $-25^{\circ} \mathrm{C} \sim 55^{\circ} \mathrm{C}$ \\
\hline Work Humidity & $5 \% \sim 95 \%$, non-condensing \\
\hline
\end{tabular}

\subsection{Al-Gehad Power Supply and Power Backup}

Power backup solution with UPS in Al-Gehad FTTH network as shown in Figure (8) guarantee the family voice and Internet service uninterruptable in 8 hours even without public power. Also there are digital online double-conversion UPS with three-phase input and three-phase output as shown in Figure (8). Adopting modular design and consisting of $10 \mathrm{kVA}$ power units (PU).

The rectifier shown in Figure (9) is a high frequency switchmode indoor DC power system. It is designed with high reliability, high efficiency and good electromagnetic compatibility and easy to maintenance. The maximum configured capacity is $600 \mathrm{~A}$ with twelve 50A-rectifier modules. It is designed for indoor middle capacity situations. 


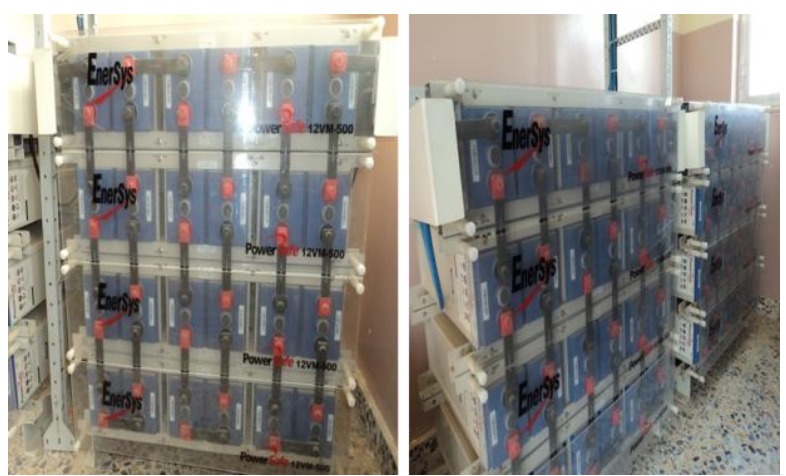

Figure 8. Al-Gehad UPS System

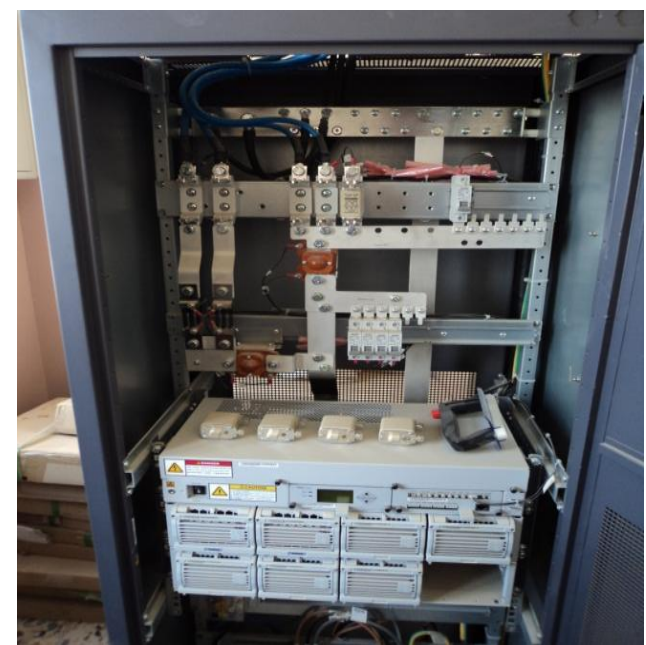

Figure 9. Al-Gehad TP48300B Rectifier

\subsection{Fiber Optic Cable Implementation}

Fiber optic cable refers to the complete assembly of fibers, strength members and jacket. Fiber optic cables come in lots of different types, depending on the number of fibers and how and where it will be installed. Choose cable carefully as the choice will affect how easy it is to install, splice or terminate and, most important, what it will cost. In Al Gehad FTTH network two types of single mode fiber optic cable are used:

a. Feeder cables of type 144F: this cable offers the highest packing density, since all the fibers are laid out in rows, typically of 12 fibers, and laid on top of each other. These way 144 fibers only have a cross section of about 1/4 inch or $6 \mathrm{~mm}$. Some cable designs use a "slotted core" with up to 6 of these 144 fiber ribbon assemblies for 864 fibers in one cable. Since its Outside Plant Cable (OPC), it's gel-filled for water blocking. It is the most important subsystem in the ODN. It uses ring structure. This subsystem is convenient for expansion of the coverage area on basis of the ensured network security.

b. Distribution cables: they contain several tightbuffered fibers bundled under the same jacket. These cables are small in size, and used for short, dry conduit runs, riser and plenum applications. The fibers are double buffered and can be directly terminated, but because their fibers are not individually reinforced, these cables need to be broken out with a "breakout box" or terminated inside a patch panel or junction box. Three types of distribution fiber cable is used in Al Gehad FTTH network 48F, 24F, and 12F. They are intermediate link connecting the feeder cable subsystem and the drop cable subsystem. It had better adopt the tree structure with the optical fiber quantities to save the engineering investment.

AutoCAD map of Al Gehad FTTH network is obtained from ITPC. Figure (10) shows part of the whole optical distribution cables map of Al-Gehad FTTH network pointed on it the whole area which will be covered by FTTH network starting from Al-Gehad exchange and extended to cover three quarters they are 887,889 , and 891 . Feeder cables, with yellow color, extended from the exchange to Fiber Distribution Terminal (FDT) cabinet, and distribution cables, with green color, are extended from Fiber Allocation Terminal (FAT) to the user terminal.

Length of each piece of feeder cables and distribution cables are mentioned, as well as the distance between two manholes, distance between FAT and manhole and the distance between two FATs. Planner called manhole loop, it is used to change the direction of feeder fiber cable, and since fiber cable cannot bend.

Each Fiber Distribution Terminal (FDT) or splitter has a number written as FDT-4 or FDT-6 and so on, and each FAT associated with a specific FDT has a number included its number and the number of DFT, for example, F-14/3 number 14 points to FAT number associated with FDT number 3. Beside the number of each FAT there is a number of serving users, for example U14 this mean that there are 14 serving users by this FAT.

\section{CONCLUSION}

The proposed model of FTTH access network based on GPON architecture is introduced. We have found that the FTTH networks have now established their economic competitiveness by providing significantly reduced operating expenses and enhanced revenue opportunities for carriers. In addition, a FTTH solution based on Wavelength Division Multiplexing (WDM), or a $\lambda$ - based structure, allows for additional flexibility and adaptability to support future services. The main motivation for the distribution architecture is to minimize the amount of optical cable that is needed for the distribution and drop fibers, which provides a low initial cost of the outside cable plant when implementing a FTTH network.

\section{ACKNOWLEDGMENTS}

The authors would like to acknowledge the support to this work by the Iraq Telecommunication and Post Company (ITPC). 


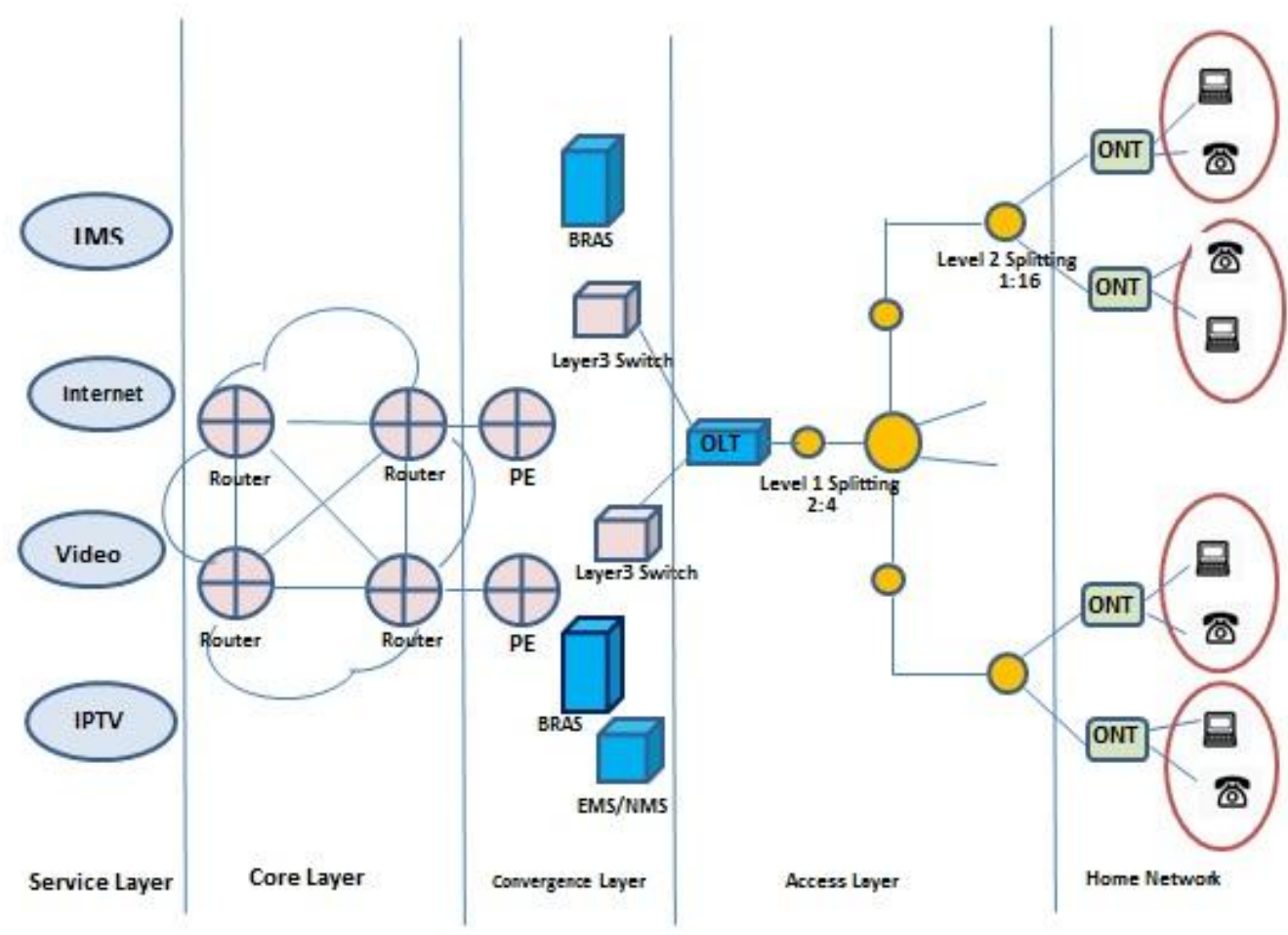

Figure 1. ITPC FTTH Access Network Architecture

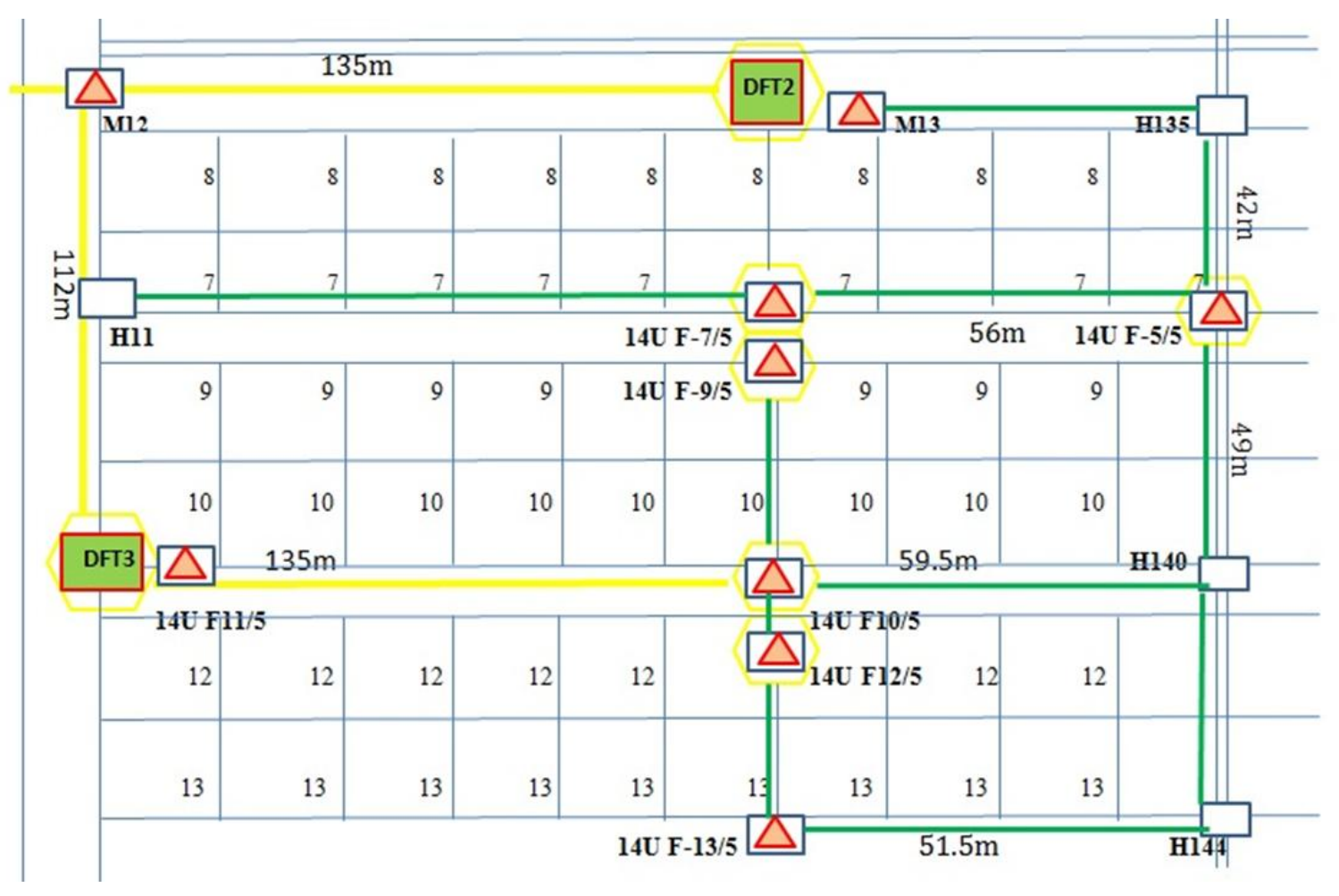

Figure 10. Distribution Cable Routing 


\section{REFERENCES}

[1] Gerd Keiser, FTTX Concepts and Applications, Photonics Comm Solutions, Inc. , John Wiley \& Sons Ltd., 2006.

[2] Cedric F. Lam,"passive optical networks: principles and practice", Elsevier Inc. 2007.

[3] P. Ossieur, X. Z. Qnetiu, J. Bauwelinck, D. Verhulst, Y. Martens, J.Vandewege and B. Stubbe, "An Overview of Passive Optical Network",Proceedings of International Symposium of Signals, Circuits and Systems, lasi, Romania, 2003.

[4] Chinlon Lin, editor, "Broadband - Optical Access Networks and Fiber-to-the-home", England: John Wiley \& Sons Ltd.; 2006.
[5] Onn Haran, Fellow and Amir Sheffer,"The importance of Dynamic Bandwidth Allocation in GPON networks", PMC-Sierra, Inc. 2008.

[6] Björn Skubic, Jiajia Chen, Jawwad Ahmed and Biswanath Mukherjee," A Comparison of Dynamic Bandwidth Allocation for EPON, GPON and NextGeneration TDM PON", IEEE Communications Magazine ,March 2009.

[7] Hesham A. Bakarman, Sahbudin Shaari and Mahamod Ismail," Simulation of $1.25 \mathrm{~Gb} / \mathrm{s}$ Downstream Transmission Performance of GPON-FTTx", IEEE 2010.

[8] Cisco systems, " The Exabyte Era",2007. 